\title{
Race: a social destruction of a biological concept
}

\author{
Neven Sesardic
}

Received: 11 August 2009/Accepted: 22 December 2009/Published online: 12 January 2010

(C) Springer Science+Business Media B.V. 2010

\begin{abstract}
It is nowadays a dominant opinion in a number of disciplines (anthropology, genetics, psychology, philosophy of science) that the taxonomy of human races does not make much biological sense. My aim is to challenge the arguments that are usually thought to invalidate the biological concept of race. I will try to show that the way "race" was defined by biologists several decades ago (by Dobzhansky and others) is in no way discredited by conceptual criticisms that are now fashionable and widely regarded as cogent. These criticisms often arbitrarily burden the biological category of race with some implausible connotations, which then opens the path for a quick eliminative move. However, when properly understood, the biological notion of race proves remarkably resistant to these deconstructive attempts. Moreover, by analyzing statements of some leading contemporary scholars who support social constructivism about race, I hope to demonstrate that their eliminativist views are actually in conflict with what the best contemporary science tells us about human genetic variation.
\end{abstract}

Keywords Race - Social constructivism - Genetics · Geographical ancestry · Human variation · Philosophy of science

Those who subscribe to the opinion that there are no human races are obviously ignorant of modern biology.

Ernst Mayr, 2002

\footnotetext{
N. Sesardic $(\bowtie)$

Lingnan University, Tuen Mun, Hong Kong

e-mail: sesardic@ln.edu.hk
} 


\section{Introduction}

A number of contemporary philosophers, anthropologists, geneticists, evolutionary biologists and psychologists have argued for some time that the concept of race does not have a biological reality. But what is actually being denied here? What exactly does it mean that a concept has (or does not have) a biological reality?

To paraphrase the title of Quine's famous article "Three Grades of Modal Involvement", the concept of race has three possible grades of biological involvement. First, the basic meaning of "race" seems to imply that, due to a common ancestry, members of a given race A will display increased genetic similarity, which will make them in some way genetically different from individuals belonging to another race, B. Second, it is frequently assumed that A-individuals will also differ systematically from B-individuals with respect to some genetically determined morphological characteristics (skin color, hair texture, facial features, etc.), with these morphological differences being the basis for the common-sense racial recognition and classification. And third, A-individuals could differ from B-individuals with respect to some genetically determined psychological characteristics as well. So in discussing the concept of race, its three grades of biological involvement are three kinds of racial differentiation that are rooted in biology: genetic, morphological and psychological.

Each of these three ways of connecting race with biology has been widely disputed. Various general arguments against the biological underpinnings of race have convinced a lot of people, although they should not have. Despite the flawed logic of most of these deconstructive attacks, the biological concept was in the end hastily and clumsily dismantled. Learned societies issued statements disowning the concept and many leading experts in the relevant fields joined in by insisting that this pure "social construction" has no counterpart in the subject matter of life sciences, that "the concept of race has no genetic or scientific basis" (Craig Venter), or that it is "biologically meaningless" (Schwartz 2001, 1392). In a very influential article it has even been suggested that the reality of human races is another common sense "truth" destined to follow the flat Earth into oblivion (Diamond 1994, 82). Similarly, in the publicly acclaimed PBS series "Race: The Power of an Illusion" (2003), anthropologist Alan Goodman said "To understand why the idea of race is a biological myth requires a major paradigm shift, an absolute paradigm shift, a shift in perspective. And for me, it's like seeing, you know, what it must have been like to understand that the world isn't flat".

In this paper I will try to bring the notion of race back into the open, dust it off a little and reevaluate its scientific status. I will separately discuss the three grades of biological involvement mentioned above: genetic, morphological and psychological differentiation.

But first a few words about a frequent attempt to undermine the concept of race by arbitrarily adding to its definition some blatantly unacceptable assumptions.

\section{Defining the race away}

Naomi Zack claims that those who believe in the existence of human races "to this day... assume the following: (1) races are made up of individuals sharing the same 
essence; (2) each race is sharply discontinuous from all others..." (Zack 2002, 63italics added).

Zack is wrong. First, as many philosophers have pointed out, the everyday concept of race "has been greatly influenced by science" (Andreasen 2005, 100, cf. Appiah 1999, 269). Therefore there is no reason to think that the ordinary notion of race would "to this day" be so rigidly determined by such a completely outdated and long discredited essentialist taxonomy. Second, it is actually dubious whether the view of races as "sharply discontinuous" groups was ever the received view in science. After all, despite the usual criticisms of the pre-Darwininan "typological" thinking, even the very first systematic scientific work on human races was not essentialist in Zack's sense, as shown in the following quotation from the book first published in 1776:

For although there seems to be so great a difference between widely separate nations, that you might easily take the inhabitants of the Cape of Good Hope, the Greenlanders, and the Circassians for so many different species of man, yet when the matter is thoroughly considered, you see that all do so run into one another, and that one variety of mankind does so sensibly pass into the other, that you cannot mark out the limits between them. (Blumenbach 2005, 98-99-italics added)

Sally Haslanger states that "our everyday racial classifications do not track meaningful biological categories". She explains: "there are no 'racial genes' responsible for the different clusters of physical or cultural differences between members of racial groups..." (Haslanger 2005, 266) Indeed, if our everyday racial classifications required the existence of some special "racial genes", any connection with currently accepted biological categories would be immediately lost. But since Haslanger gives no support at all for her claim that the common sense notion of race is inextricably linked with such a demonstrably false assumption, it is fair to conclude that she has actually done nothing to show that "our everyday racial classifications do not track meaningful biological categories".

Philip Kitcher also sets up a similar straw man concept, which he then easily knocks down:

Contemporary genetic studies of human populations have revealed that there are no alleles distinctive of this race or of that, and, although a few researchers like J. Philippe Rushton-"ogre naturalists," as Ian Hacking aptly dubs them-continue to seek such simple genetic differences, there is a widespread consensus among anthropologists that races are not "biologically real". (Kitcher 2007, 293-4)

Among contemporary scientists, Rushton is one of the main defenders of the biological reality of the everyday concept of race. Anyone who is even superficially acquainted with his work will recognize how unfair and inappropriate it is to refer to his research program as seeking "alleles distinctive of this race or of that". In fact, if Kitcher's parody were true, it would be inexplicable how it could happen that Rushton's articles containing such scientific nonsense were favorably judged by academic referees and accepted for publication in leading scholarly journals. The 
truth, of course, is that Rushton's real ideas bear no resemblance to how Kitcher pictures them. Instead of being discussed and perhaps criticized, Rushton is here only quickly dismissed without his views being as much as presented.

Antony Appiah also explodes the biological concept of race by capriciously inflating it with clearly unacceptable essentialist connotations. In discussing a potential grounding of "race" in biology, the only position that he considers is the view "that there are heritable characteristics, possessed by members of our species, that allow us to divide human beings into a small set of races, in such a way that all the members of these races share certain traits and tendencies with each other that they do not share with members of any other race. These traits and tendencies characteristic of a race constitute, on the racialist view, a sort of racial essence" (Appiah 1990, 4-5-italics added; cf. Appiah 2006, 363). Appiah rightly says that such a view is scientifically untenable but he wrongly concludes from this that the concept of race is thereby shown to have no connection with biology. Apparently he never envisages the obvious possibility that his essentialist non-starter is not the only option, and that the notion of race might still be biological, if interpreted in a more charitable and more sophisticated way. It is puzzling why Appiah is ignoring the dog that is so loudly barking here and seeking attention: a biologically informed but non-essentialist concept of race.

It is true that the everyday concept of race does presuppose some degree of phenotypic similarity between the groups called "races". But surely this phenotypic similarity does not have to be manifested necessarily in such a way that, in case of two distinct racial groups $\mathrm{A}$ and $\mathrm{B}$, all members of group A would have to share certain characteristic F, and that characteristic F would also have to be absent in all members of group B. More complex and much more plausible forms of racial phenotypic similarity are possible (as will be illustrated in "Morphological differences").

Ron Mallon follows Appiah, and in discussing race focuses only on this crude form of similarity. He says that historically races were believed to be characterized by properties that "are shared by all and only the members of a race" (Mallon 2006, 528-italics added). Again, after justifiably rejecting this view, Mallon never goes back to look at some more viable versions of the biological race concept that would be based on similarity. As a result, his overview of different standpoints on race turns out to be seriously incomplete: the only biology-based concept of race that he discusses is the cladistic "racial population naturalism", which does not include the claim that races are genetically or morphologically distinguishable from one another. So any similarity-laden view of race simply falls through the cracks. The similarity-driven concept of race is addressed only in its essentialist version ("shared by all and only the members of a race") and rightfully dismissed as anachronistic and untenable. But its subtler and much more interesting version (which exists in the literature) never receives any consideration.

Nevertheless, Mallon's sin of omission did not preclude the Stanford Encyclopedia of Philosophy from endorsing his views in its recent article on race and concluding, relying mainly on his arguments, that "the biological conception of race is philosophically and scientifically dead" (James 2008). 
It appears that those who attempt to deconstruct the concept of race by gratuitously burdening it with essentialist connotations ("discrete", "non-overlapping", "discontinuous", "defined by racial markers", "racial genes", etc.) are unaware that their criticism has already been addressed by Dobzhansky more than 40 years ago:

Professor Fried has correctly pointed out that there is no careful and objective definition of race that would permit delimitation of races as exact, nonoverlapping, discrete entities. Indeed, such criteria do not exist because if they did, we would not have races, we would have distinct species. (Dobzhansky in Mead $1968,165)$

In fact, Dobzhansky's argument should be taken one step further: the essentialist requirement is so unrealistically demanding that, if this criterion were applied, even the species concept would fail to pass muster: "In practice, the characters that define a species will not be present in all members of that species and absent from all members of other species. Nature is too variable" (Ridley 2004, 349).

Oddly, even the scholars who have been at the very forefront of empirical research on race are prone to use fallacious reasoning in order to downplay the importance of that concept. For instance, Cavalli-Sforza, geneticist and the lead author of the path-breaking History and Geography of Human Genes (CavalliSforza et al. 1994), states in a book co-authored with Walter Bodmer: "Races are, in fact, generally very far from pure and, as a result, any classification of races is arbitrary, imperfect, and difficult" (Bodmer and Cavalli-Sforza 1976-italics added). Is any classification of races imperfect? Yes. Difficult? Perhaps. But arbitrary? No, this certainly does not follow from the premise, "as a result".

Speaking about Cavalli-Sforza, it is interesting that he tried to defuse potential political attacks on his research by a simple and sometimes surprisingly effective rhetorical ploy. At one point he just stopped using the term "race" and replaced it with a much less loaded expression "human population", which in many contexts he actually used more or less with the same meaning as "race". On one occasion this terminological switch gave rise to an amusingly ironic development, as described in the following episode involving Cavalli-Sforza's collaborator, Edwards:

When in the 1960s I started working on the problem of reconstructing the course of human evolution from data on the frequencies of blood-group genes my colleague Luca Cavalli-Sforza and I sometimes unconsciously used the word 'race' interchangeably with 'population' in our publications. In one popular account, I wrote naturally of 'the present races of man'. Quite recently I quoted the passage in an Italian publication, so it needed translating. Sensitive to the modern misgivings over the use of the word 'race', CavalliSforza suggested I change it to 'population'. At first I was reluctant to do so on the grounds that quotations should be accurate and not altered to meet contemporary sensibilities. But he pointed out that, as the original author, I was the only person who could possibly object. I changed 'present races of man' to 'present populations of man' and sent the paper to be translated into 
Italian. When it was published the translator had rendered the phrase as

'le razze umane moderne'. (Edwards undated, unpublished manuscript)

So, the whole process unfolded in three stages. First, it began with the original text containing the word "race". Then with time the term started to sound unacceptable or jarring to some people, and consequently the pressure of the new linguistic practice transformed it into "population". Finally, an easygoing and politically unconcerned Italian translator just went ahead and turned it back into "razza".

\section{Genetic differences}

In biology, the concept of "race" is often regarded as synonymous with "subspecies". Subspecies are populations of organisms that, despite belonging to the same species, differ among themselves with respect to frequencies of alternative alleles at a number of loci. These differences are the result of these populations being at least partly isolated from one another long enough for a genetic differentiation to develop. Research has shown that, indeed, groups of people of significantly different geographical ancestries do differ from one another genetically: when compared on many genetic loci these groups have different frequencies of different alleles.

Is this empirical fact sufficient to vindicate the notion of human subspecies or human races? Many say "No", offering two main reasons for their skepticism: first, that the genetic variation between the groups is too small (compared to the genetic variation within groups), and second, that the groups formed on the basis of genetic similarity do not actually correspond to common sense races.

Too small to matter?

Since the publication of Richard Lewontin's widely cited article (Lewontin 1972), it has been a matter of scientific consensus that a much smaller part of the total human genetic variation is between the races than within the races. Lewontin estimated the inter-racial variation comprises only about $7 \%$ of the total genetic variation in the human species. Some philosophers think that this numerical fact alone shows that the biological concept of subspecies (or race) is inapplicable to humans (e.g., Machery and Faucher 2005, 1208-1209; Richardson 2000, 847). Robin Andreasen also uses the relatively small between-group genetic variation to argue that "if we focus on the synchronic question - is there any justification for dividing current populations into races-the answer may very well be 'no'" (Andreasen 1998, 215, cf. 2000, S663; Mallon 2006, 529). In a similar vein, Ned Block tries to undermine the importance of race by mentioning that only about $7 \%$ of all human genetic variation lies between the major races (Block 1995, 112, 115). All these philosophers seem to consider the anti-race import of that low percentage figure so cogent and straightforward that they do not even deem it necessary to clarify how it is supposed to establish their conclusion. Yet their reasoning is fallacious: the 
mere fact that the between-group genetic variation is many times smaller than the within-group variation does not actually preclude racial categorization from making a lot of genetic sense.

To think otherwise is to commit a statistical mistake that has recently been labeled "Lewontin's fallacy" (see Edwards 2003). An argument that is due to Lewontin and that has been uncritically accepted by almost all philosophers is that racial classification is of virtually no genetic or biological significance just because the genetic differences between the races on a number of arbitrarily selected loci are typically found to be swamped by the corresponding within-race differences. But as Edwards has shown, Lewontin completely ignored the aggregation effect of these inter-group differences in allele frequencies on different loci, which could (and arguably does) support a racial taxonomy-without a need for a very big average variation between the races on a locus-by-locus basis. Even with Lewontin's condition satisfied (i.e., the within-group variation being much larger than the between-group variation), a clear group structure can still emerge on the basis of these aggregate properties of populations. It should be emphasized that Lewontin's fallacy was exposed long before Edwards' article in 2003. An especially clear explanation is given in Mitton (1977) and (1978), the articles that somehow missed the attention of most scholars, including Edwards himself (personal communication).

Look at a simple (fictitious) illustration in Fig. 1. There are two groups of objects, represented in the graph by triangles and squares, respectively. For any of these forty objects one can read off its numerical value on either of the two dimensions (on the $X$ and $Y$ axis). On each of the two dimensions, considered

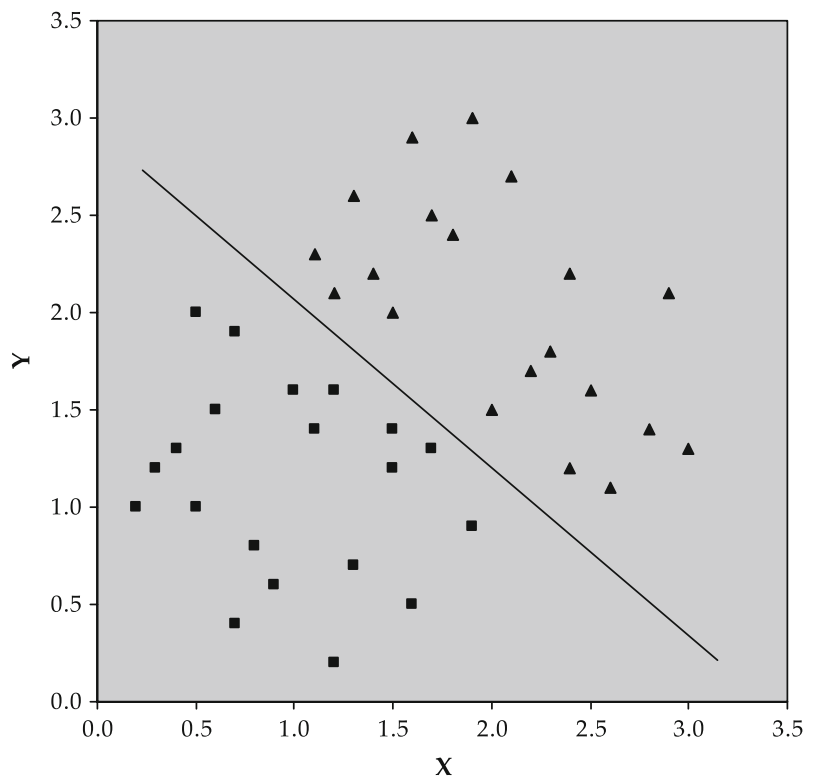

Fig. 1 Clusters emerging in a two-dimensional perspective 
separately, triangles and squares overlap a lot and there is no way to segregate the two shapes into two distinct groups. Put differently, any way you choose to split the $X$ axis into two parts, you will never be able to get all and only the triangles having their $X$-value on one side of that cut (and consequently all the squares with their $X$ values on the opposite side of the cut). The same is true about the $Y$ axis. However, combining the two dimensions makes it possible to appreciate that the two groups indeed fall apart and that they can be divided off from each other by a straight line.

It bears emphasis that with respect to each of the two variables $(X$ and $Y$ ) the within-group variation is larger than the between-group variation, and yet the group structure emerges already in the two-dimensional graph. Adding one more dimension might further strengthen the group separation and make the segmentation even clearer and more robust. Adding yet another dimension could push the groups still further apart... And so forth. I haven't used some of the existing graphs that make the same point because they assume that there is a $X-Y$ correlation within groups, which is both unnecessary and disanalogous to the case under discussion (differences within and between human races).

Returning to the topic of human genetic variation, we are now in a better position to diagnose the source of Lewontin's fallacy. The figure of only $7-10 \%$ of total genetic variation belonging to the variation between the races actually refers to the inter-racial portion of variation that is averaged over the separate contributions of a number of individual genetic indicators that were sampled in different studies. In other words, this information is completely restricted to an iterated single-dimensionpoint-of-view. Any structure that might exist at the level of the aggregation of the inter-group genetic differences is absolutely invisible from that essentially onedimensional perspective.

Lewontin's univariate approach to the conceptualization of race is particularly clear when he asks: "How much difference in the frequencies of $\mathrm{A}, \mathrm{B}, \mathrm{AB}$, and $\mathrm{O}$ blood groups does one require before deciding that it is large enough to declare two local populations are in separate 'races'?" (Lewontin 1987, 200) This is the wrong question completely. Races are not distinguished from one another by some specially big difference of allelic frequencies in one trait, but rather by a combination of a number of small or moderate differences in many traits. That is, e pluribus, not ex uno.

Here is another way of explaining Lewontin's fallacy, by using an analogy with two biased coins. Assume that coin 1 is slightly biased toward heads, with its $p(\mathrm{H})=0.6$, whereas coin 2 is biased in the opposite direction, with its $p(\mathrm{H})=0.4$. If one of the two coins is randomly chosen and then flipped, observing the outcome (heads or tails) will not help us much in guessing which of these two coins was actually flipped. On average, our best guess (that it was the coin with the bias toward the observed outcome) will be correct only slightly above the chance level of 0.5 . To be precise, our success rate with this strategy will be $60 \%$. But with the increasing number of tosses of the selected coin, our predictive ability will become better and better. Consider the situation in Table 1 that represents 11 flips of the unknown coin, which in every trial has the same probability of heads (either 0.6 or $0.4)$. 
Table 1 Coin 1 or coin 2?

\begin{tabular}{lll}
\hline & Coin 1 & Coin 2 \\
\hline Flip 1 & $p(\mathrm{H})=0.6$ & $p(\mathrm{H})=0.4$ \\
Flip 2 & $p(\mathrm{H})=0.6$ & $p(\mathrm{H})=0.4$ \\
Flip 3 & $p(\mathrm{H})=0.6$ & $p(\mathrm{H})=0.4$ \\
Flip 4 & $p(\mathrm{H})=0.6$ & $p(\mathrm{H})=0.4$ \\
Flip 5 & $p(\mathrm{H})=0.6$ & $p(\mathrm{H})=0.4$ \\
Flip 6 & $p(\mathrm{H})=0.6$ & $p(\mathrm{H})=0.4$ \\
Flip 7 & $p(\mathrm{H})=0.6$ & $p(\mathrm{H})=0.4$ \\
Flip 8 & $p(\mathrm{H})=0.6$ & $p(\mathrm{H})=0.4$ \\
Flip 9 & $p(\mathrm{H})=0.6$ & $p(\mathrm{H})=0.4$ \\
Flip 10 & $p(\mathrm{H})=0.6$ & $p(\mathrm{H})=0.4$ \\
Flip 11 & $p(\mathrm{H})=0.6$ & $p(\mathrm{H})=0.4$ \\
\hline
\end{tabular}

Based on the observed outcomes of these 11 flips, we have to infer which of the two coins was in fact tossed (i.e., which of the two columns represents the reality).

How often will we be right? First, notice that in these eleven tosses either there will be more heads than tails or more tails than heads. Obviously the probability of more heads $(\mathrm{MH})$ is higher with coin 1 than with coin 2 . The binomial probability calculator tells us that $p\left(\mathrm{MH} \mid \mathrm{C}_{1}\right)$ is 0.753 , and $p\left(\mathrm{MHIC}_{2}\right)$ is 0.247 . Bayes's theorem then gives us the answer to the specific question we are interested in: what is $p\left(\mathrm{C}_{1} \mid \mathrm{MH}\right)$ ?

$$
\begin{aligned}
p\left(\mathrm{C}_{1} \mid \mathrm{MH}\right) & =\frac{p\left(\mathrm{C}_{1}\right) \times p\left(\mathrm{MH} \mid \mathrm{C}_{1}\right)}{p\left(\mathrm{C}_{1}\right) \times p\left(\mathrm{MH} \mid \mathrm{C}_{1}\right)+p\left(\mathrm{C}_{2}\right) \times p\left(\mathrm{MH} \mid \mathrm{C}_{2}\right)}=\frac{\frac{1}{2} \times 0.753}{\frac{1}{2} \times 0.753+\frac{1}{2} \times 0.247} \\
& =0.753
\end{aligned}
$$

Relying on the information that in 11 tosses there were more heads than tails (or the other way around, as the case might be) we will be able to guess correctly which coin was selected in approximately $75 \%$ of the cases.

How about the case with 101 flips? Here using the same reasoning as above, the probability that we will be right about the coin will rise to 0.979 .

What will happen when there are, say, 1,001 flips? In that situation our probabilistic inference will lead us to the wrong conclusion only in about one out of 10 billion cases. We have reached the region of virtual certainty.

The lesson here is that although inferring the identity of the coin from the outcome of any individual flip is indeed highly fallible and unreliable, using the joint information about more and more flips can improve our predictive ability significantly. By just increasing the number of tosses we can approach the limit of perfect accuracy as close as we like.

To see how all this connects with Lewontin's fallacy let us move from coin tossing to genetics. Let us assume that an individual is randomly selected from one of two populations. Our task is to guess to which of these two populations the individual belongs, given that these two groups have different frequencies of two 
Table 2 Population 1 or population 2 ?

\begin{tabular}{lll}
\hline & An individual from $\mathrm{P}_{1}$ & An individual from $\mathrm{P}_{2}$ \\
\hline Locus 1 & $p\left(\mathrm{~A}_{1}\right)=0.6$ & $p\left(\mathrm{~A}_{1}\right)=0.4$ \\
Locus 2 & $p\left(\mathrm{~A}_{1}\right)=0.6$ & $p\left(\mathrm{~A}_{1}\right)=0.4$ \\
Locus 3 & $p\left(\mathrm{~A}_{1}\right)=0.6$ & $p\left(\mathrm{~A}_{1}\right)=0.4$ \\
Locus 4 & $p\left(\mathrm{~A}_{1}\right)=0.6$ & $p\left(\mathrm{~A}_{1}\right)=0.4$ \\
Locus 5 & $p\left(\mathrm{~A}_{1}\right)=0.6$ & $p\left(\mathrm{~A}_{1}\right)=0.4$ \\
Locus 6 & $p\left(\mathrm{~A}_{1}\right)=0.6$ & $p\left(\mathrm{~A}_{1}\right)=0.4$ \\
Locus 7 & $p\left(\mathrm{~A}_{1}\right)=0.6$ & $p\left(\mathrm{~A}_{1}\right)=0.4$ \\
Locus 8 & $p\left(\mathrm{~A}_{1}\right)=0.6$ & $p\left(\mathrm{~A}_{1}\right)=0.4$ \\
Locus 9 & $p\left(\mathrm{~A}_{1}\right)=0.6$ & $p\left(\mathrm{~A}_{1}\right)=0.4$ \\
Locus 10 & $p\left(\mathrm{~A}_{1}\right)=0.6$ & $p\left(\mathrm{~A}_{1}\right)=0.4$ \\
Locus 11 & $p\left(\mathrm{~A}_{1}\right)=0.6$ & $p\left(\mathrm{~A}_{1}\right)=0.4$ \\
\hline
\end{tabular}

alternatives alleles on a number of loci. For simplicity, suppose (following Edwards 2003) that for any particular locus, whichever of its two alleles we take, its frequency will be 0.6 in one group and 0.4 in the other. Now for every of these biallelic loci I will label the allele that is more frequent in population $\mathrm{P}_{1}$ as allele $\mathrm{A}_{1}$ (for that locus). And any allele that is alternative to $A_{1}$ on a given locus will be called $A_{2}$ (for that locus). Obviously, $A_{2}$ will always be more frequent than $A_{1}$ in population $\mathrm{P}_{2}$.

Table 2 shows a situation in which eleven loci are considered and which is so structurally similar to the two-coin example that it contains the same numerical values as Table 1 . So the same calculation must apply.

If by using the information from only one locus we decide to assign a randomly chosen individual to the population in which the actually observed allele is more frequent than its alternative, we will get the wrong result in 2 out of 5 cases. If using 11 loci and assigning the individual to the population in which the majority of the observed alleles are more frequent than their alternatives, the rate of error will be around 1 out of 4 . With 101 loci, the probability of mistake with this method will be approximately 1 out of 50. Finally, with 1,001 loci the wrong group attribution will be so spectacularly unlikely that for all practical purposes our inference will be error-free. ${ }^{1}$

Therefore, contra Lewontin, the racial classification that is based on a number of genetic differences between populations may well be extremely reliable and robust, despite the fact that any single of those genetic between-population differences remains, in itself, a very poor predictor of racial membership.

\footnotetext{
${ }^{1}$ Here is the translation manual for the coin analogy. The two coins with opposite biases (towards heads or tails) correspond to the two individuals from two different populations that have opposite allelic biases (towards $\mathrm{A}_{1}$ or $\mathrm{A}_{2}$ ). Different flips of the coin correspond to different loci. The heads or tails outcome in a particular coin throw corresponds to the $\mathrm{A}_{1}$ or $\mathrm{A}_{2}$ outcome on a particular locus.
} 
Races $\neq$ groups based on genetic similarity?

Fine, the argument could go (and actually did), it may well be that heterogeneous human populations indeed cluster into a number of distinct groups based on the multivariate genetic similarity, but it may still turn out that these gene-based clusters do not correspond to common-sense races at all. In that case, the colloquial racial classification would still be left with no support from biology: "While we argue that there likely are a variety of identifiable and biologically meaningful races, these will not correspond to folk racial categories" (Pigliucci and Kaplan 2003, 1161).

Ironically, empirical knowledge about race and genetic is advancing so fast that Pigliucci's and Kaplan's prediction was already refuted while the article with their bold claim was still in print. In an important paper that came out in Science at the very end of 2002, a group of geneticists showed that the analysis of multilocus genotypes of 1,056 individuals from 52 populations did allow an inference of group structure and that, furthermore, five clusters derived from that analysis of purely genetic similarities corresponded largely to major geographic regions (Rosenberg et al. 2002). This is an important discovery that makes it much more difficult than before to claim that race is entirely disconnected from genetics.

Ian Hacking was also unlucky with the following scientific prophecy that he put forward: "Science might have revealed an endless number of differences between the races that are not consequences of the marks by which we distinguish them, namely color and physiognomy. But science has not done so, and almost certainly will not". (Hacking 2005, 104) As yet another indication of how quickly this research area is moving forward, Hacking has backpedalled considerably in an article published just 1 year later, adopting a much more guarded tone and now explicitly conceding that "stereotypical features of race are associated both with ancestral geographical origin and, to some extent, with genetic markers" (Hacking 2006, 86).

There have been some attempts to downplay the importance of the results presented in Rosenberg et al. (2002). For instance, it was said that the major geographical regions, for which the correlation with genetic clusters was observed, only loosely correspond to social categories of race (Bonham et al. 2005, 12) and that self-reported race (which better represents the common sense notion of race) would not necessarily show the same level of correlation with genetic clusters (Barbujani 2005, 521). These complaints were raised in 2005, but they were put into doubt by a new study that was published in December of the same year.

A group of researchers led by geneticist Neil Risch analyzed genetic data for 326 microsatellite markers on a sample of 3,636 subjects from the United States and Taiwan. The subjects identified themselves as belonging to one of the four racial groups (white, African American, East Asian and Hispanic). The genetic cluster analysis of the data produced four major clusters, whose correspondence with the four self reported races was near-perfect: the genetic cluster membership and self-identified race coincided in as many as $99.9 \%$ of the cases. Commenting on this result in an interview, Risch said that if the concept of race is regarded as genetically suspect because of this extremely low discordance rate of $0.1 \%$, then any classificatory scheme should be rejected as well because "any category you come up 
with is going to be imperfect" (Gitschier 2005, 4). He added that if nothing short of a perfect correspondence could legitimate the genetic basis of a common sense category, then it would follow that even the distinction between "male" and "female" has nothing to do with genetics either, since in his study a discordance rate between self-reported sex and markers on the $\mathrm{X}$ chromosome was actually higher that the discordance rate between self-reported race and the genetic cluster membership.

A good measure of the robustness of racial genetic differentiation is the answer to the following question: "How often does it happen that a pair of individuals from one population is genetically more dissimilar than two individuals chosen from two different populations?" In fact, if many thousands of loci are used as a basis for judging genetic similarity and when individuals are sampled from geographically separated populations, the correct answer, which many will probably find surprising, is: "Never" (Witherspoon et al. 2007, 357).

To illustrate how, due to recent developments in science, a chasm opened between the consensus in philosophy of biology and views of some cutting edge geneticists, let me juxtapose contrasting statements of two authorities in these two fields. David Hull, philosopher: "The subdivisions of Homo sapiens that experts recognize do not come close to coinciding with the 'races' of ordinary people" (Hull 1998, 366). Neil Risch and his team of geneticists: "The correspondence between genetic cluster and self-identified race/ethnicity is remarkably high... Accordingly, in this case, major self-identified race/ethnicity and genetic cluster are effectively synonymous" (Tang et al. 2005, 271-italics added). In another paper Risch stated that "effectively, these population genetic studies have recapitulated the classical definition of races based on continental ancestry" (Risch et al. 2002).

This does not mean, of course, that Risch's results by themselves conclusively establish the biological reality of race or refute social constructivism about that concept. Questions can be (and have been) raised about whether the same outcome would be obtained for other racial categories, or with a sample of people with more mixed ancestries, or on a more fine-grained scale, etc. My point is merely that in view of these new studies it becomes harder to accept the widespread but often unsubstantiated claim about the biological meaninglessness of race. Those who support this view ought to stop relying on simplistic and time-worn arguments that have been largely discredited. Instead, they should make contact with the most recent exciting developments in genetics and deal with the best contemporary attempts to rehabilitate the biological foundations of race.

Another way to illustrate how recent advances in empirical knowledge have changed the terms of the debate about race is to contrast the statements of the two high-profile geneticists, Craig Venter and Francis Collins. In June of 2000, at the White House press conference in celebration of the completion of the sequencing of the human genome, Craig Venter famously said that "the concept of race has no genetic or scientific basis". It was only 4 years later that Francis Collins (the leader of the rival research team in the Human Genome race) decided that the studies that have appeared in the meantime made it necessary for him to disagree: "Increasing scientific evidence, however, indicates that genetic variation can be used to make a reasonably accurate prediction of geographic origins of an individual, at least if that 
individual's grandparents all came from the same part of the world. As those ancestral origins in many cases have a correlation, albeit often imprecise, with selfidentified race or ethnicity, it is not strictly true that race or ethnicity has no biological connection" (Collins 2004, S13, italics added).

\section{Morphological differences}

In everyday life we classify people into different races on the basis of their external appearance. The morphological features used for this purpose include skin color, hair texture, bone structure, facial features, etc. Although we are in general pretty accurate in assigning people to different racial groups, there is an influential argument purporting to show that any such phenotypic categories are actually arbitrary and lack objective validity. This so-called "independent variation argument" or "the fact of discordance" has been accepted by a number of philosophers (e.g., Andreasen 2004, 428, 2005, 94, 2008, 484; Machery and Faucher 2005, 1209; Glasgow 2009, 88; Appiah 1996, 99; see also Appiah and Gutman 1998, 116). These philosophers rely (disjunctively) on the following sources and treat them as entirely authoritative:

If one genetic character is used, it is possible to divide a species into subspecies according to the variation in this character. If two characters are used, it may still be possible, but there will be some "problem populations", which, if you are an anthropologist, will be labeled composite or mixed. As the number of characters increases it becomes more nearly impossible to determine what the "actual races really are". (Livingstone 1962).

There are many different, equally valid procedures for defining races, and those different procedures yield very different classifications... Faced with such differing classifications, many anthropologists today conclude that one cannot recognize any human races at all. (Diamond 1994, 84)

The success of racial classification depends on the number of traits used in ordering the races. A single trait such as skin color will result in a classification system that is easily determined. Add another trait and classification becomes a more difficult task, and there usually are groups that cannot be classified. As you increase the number of traits, the problems in racial classification become insurmountable. (Brown and Armelagos 2001, 34)

It is interesting that none of these sources cites any empirical evidence for these race-undermining claims. Furthermore, these claims clearly go against the entrenched common sense belief that racial recognition is not actually based on a single trait (like skin color) but rather on a number of characteristics that are to a certain extent concordant and that jointly make the classification not only possible but fairly reliable as well (a point that Diamond himself actually acknowledges sotto voce but which, buried at the end of his article, has been completely lost on most readers amidst his thundering denunciations of the race concept). Worse still, forensic anthropologists are quite successful in correctly inferring a person's race from the skeletal characteristics of human remains, which would of course be 
impossible if the statements in the above quotations were true. This prompted one bewildered and exasperated scientist to write an article with a provocative title: "If Races Do Not Exist, Why Are Forensic Anthropologists So Good at Identifying Them?" (Sauer 1992).

Sauer explained that in forensic anthropology race is assigned with high probability on the basis of an algorithm that combines a series of measurements. According to him, it is taken for granted among forensic anthropologists that race is determinable from the skull and postcranium, and "if such a determination is not possible, the problem is usually attributed to the incomplete nature of the remains or mixed ancestry" (ibid. p. 109).

Indeed, a quick look into the literature confirms this. For instance, a study that covered 17 populations over the world and that relied on 34 different measurements managed to assign $98 \%$ of the specimens to their correct major racial group (Brues 1990, 6). Another more recent study had a success rate of $80 \%$ in distinguishing between American Whites and Blacks, although it used just two variables. With seven variables, however, it reached the reliability of $95 \%$, and with 19 variables the probability of correct classification rose to 97\% (Ousley et al. 2009). Also, estimating generally the reliability of attributing a given data point to one of the five racial categories, another team of experts calculated that under some realistic conditions it is sufficient to use as few as 13 characteristics to have the posterior probability of the correct classification attain the value of 99\% (Konigsberg et al. 2009).

The empirical reality appears to refute decisively the claim so confidently advocated by many philosophers that "as the number of traits increases, racial classification becomes increasingly difficult" (Andreasen 2004, 428), or that "multiplying phenotypic racial traits has the result ... that ... they correlate with one another in no particular order, throwing the alleged features for biological racial reality into an unorganized mess" (Glasgow 2009, 88). This is exactly backwards: multiplying relevant phenotypic racial traits brings more order and structure, and indeed lays ground for an objective biological classification.

Here is another example of conflicting statements coming from philosophers and working scientists. Philosophers: "Assigning an individual to a race does not buy the inferential power you are usually warranted to expect from a biological kind term" (Machery and Faucher 2005, 1209). Geneticists: "It may be possible to infer something about an individual phenotype from knowledge of his or her ancestry" (Witherspoon et al. 2007, 358).

Philosophers have put too much trust in those strongly worded proclamations against the reality of race that are often issued to the wider public by high-profile scientists or learned societies. The problem with these public statements about such a politically sensitive issue is that they are not always driven just by a desire to transmit current knowledge. They do not necessarily correspond to what is really going on in scientific discussions in peer-reviewed journals. As mentioned above, it is particularly in physical anthropology that there is this acute clash between declarations directed to the public at large and the actual scientific practice, with the former often being governed less by science and more by "the reasons of the heart". This kind of a homo duplex situation produces a lot of frustration and confusion, but it has also once prompted a comment that those anthropologists who 
deny that races exist "have their heart, but not their heads in the right place" (cited in Gill 1990, viii).

One of the leading physical anthropologists warned about the tendency of some scientists to misrepresent the true view of their scientific community. He said that the idea widely propagated by many scientists that race is only skin deep "is simply not true, as any experienced forensic anthropologist will affirm" (Gill 2000). He went further and stated that the bias of the race-denial faction "seems to stem largely from socio-political motivation and not science at all" (ibid.). And finally: "At the beginning of the twenty-first century, even as a majority of biological anthropologists favor the reality of the race perspective, not one introductory textbook of physical anthropology even presents that perspective as a possibility. In a case as flagrant as this, we are not dealing with science but rather with blatant, politically motivated censorship" (ibid.).

There is also evidence from a content-analysis of the scientific literature that in the very period of the widespread public denigration of the race concept, the racial terms were actually used with increased frequency in scientific publications: "Based upon my findings I argue that the category of race only seemingly disappeared from scientific discourse after World War II and has had a fluctuating yet continuous use during the time span from 1946 to 2003, and has even become more pronounced from the early 1970s on" (Gissis 2008, 438-italics in the original).

Some other scientists agree with Gill that race denial is not based merely on scientific considerations: "The proposal to scrap the concept of race altogether is currently only one extreme in a range of views. It is certainly not shared by all anthropologists and is by no means the majority opinion of the public at large. It appears to be a conclusion reached more on the basis of political and philosophical creeds than on scientific arguments" (Klein and Takahata 2002, 384).

These are strong words and I am not suggesting that we should immediately agree with them. But if, as seems to be the case, many serious and responsible scientists complain that the scientific opinion in their disciplines has been badly misrepresented because of the pressure of political correctness, there is every reason to be very cautious and make an effort to study primary sources, rather than rely too heavily on scientists' pronouncements and proclamations addressed to the general public. Given this smoke and mirror situation in the debate about such a politicized issue as race, where emotions run high and where huge dangers of a wrong step are obvious to everyone, do not take at face value what scientists merely say about these topics. Instead, look at what they actually do about it in their real work.

As Henry Harpending astutely observed: "A poll about views of race would be like a poll about Marxism in East Germany in 1980. Everyone would lie" (Harpending 2000).

\section{Psychological differences}

Is there some reason to believe that some of the psychological differences between the races (like, for instance, the observed IQ differences between racial 
groups) are at least partly due to genetic differences between them? I will argue here that the answer to that question is not an unequivocal and resounding "No", as many philosophers and scientists are asserting. The affirmative answer cannot be rejected out of hand or treated as completely unfounded (as is often done), because it is actually supported by a number of empirical arguments that have considerable strength and legitimacy. For a recent overview of the literature and a forceful defense of the hereditarian position in this debate see Rushton and Jensen (2005).

Both in philosophy in general and in philosophy of science it is the received wisdom that the hereditarianism about group psychological differences lacks any plausibility and should not be considered as a serious empirical hypothesis. The problem, however, is that this received wisdom is not the result of a detailed analysis of all the existing arguments pro and contra. With the exception of the maverick Michael Levin, a philosopher who has an excellent command of the relevant literature and is also an outspoken critic of pure environmentalism (Levin 1997), other philosophers who discuss this topic merely gesture at the alleged weaknesses or a "pseudo-scientific" nature of hereditarianism, but typically without engaging at all with the specifics of the controversy between hereditarianism and pure environmentalism about racial psychological differences.

We are told, for instance, that science has shown that morphological differences between the races are "not correlated with traits that are humanly significant" (Hardimon 2003, 455), that "the belief that racial differences are anything more than superficial is a repugnant error" (Hacking 2005, 102-103), that "apart from a small handful of arbitrarily selected visible characteristics, the members of different races are not all that different" (Andreasen 2000, S663), that if "race" is supposed to refer to inherent behavioral and temperamental differences then "race is an illusion" (Glasgow 2009, 118), and that race is "at most a matter of physical characteristics that can have no bearing on anyone's abilities or moral character" (Dummett 2004, 31). No citations are ever provided to support these empirical claims.

Even when an argument against hereditarianism is offered, it is often weak and completely misses the point. For reasons of space I will here give just two characteristic illustrations of how cavalierly scientists and philosophers cut this Gordian knot in order to reach a desirable conclusion.

After raising his famous "Yali's question" about the economic backwardness of New Guineans ("Why white people have so much cargo and New Guinean so little?"), Jared Diamond briefly considers a possibility that a genetic difference in cognitive ability between the two groups might partly account for the observed disparity in their economic development. But although most studies indeed put the IQ of New Guineans consistently far below 100 (the white mean), Diamond immediately rejects the genetic hypothesis for the following reason: "To me, any explanation based on race is absurd. I know too many really smart New Guineans to believe there is anything genetically inferior about them" (Diamond 2005). It is easy to see that Diamond's objection to hereditarianism has no force, and that such a reasoning would be at once recognized as a blatant fallacy in any other context. Just consider an entirely analogical and equally faulty inference: "Any explanation of the difference in height between men and women that is based on genetics is absurd. 
I know too many tall women to believe that there is anything genetic about their comparatively lower height".

Another illustration is related to a well known fact that, statistically, the incidence of criminal activity is significantly higher in some racial groups than others. How can this be explained? Is this entirely the result of different environmental influences, or is at least a part of that disparity perhaps due to genetic differences between the two groups? There is a huge literature on this issue, which is notoriously dominated by uncertainties and honest disagreements among social scientists. Philip Kitcher, however, proposes a quick resolution of this debate: "Young men with dark skin are not more likely to commit crime because of the darkness of the skin or because the alleles that code for proteins that increase melanin concentrations in the skin have some psychological side effect, but because they are poor, undereducated, given fewer opportunities, and so on" (Kitcher 2007, 310). Notice how hereditarianism is presented here in a wildly implausible form as hypothesizing that a disposition toward criminal behavior is perhaps caused by the darkness of the skin (?) or is just a side-effect of those alleles that increase melanin concentration. Needless to say, no scholar has ever defended such a silly explanation.

Similarly, Kitcher writes elsewhere: "Unless we are profoundly deceived, there are some readily identifiable features of the physical and social environment that have major impact: rates of crime are much higher in decaying inner cities, but I doubt that there is a 'violence' allele that has the pleiotropic effect of sending its bearers into grim urban environments" (Kitcher 2003, 294).

Again, Kitcher presents the debate between the two rival explanations of criminality in such a way that his environmentalist hypothesis has a certain air of plausibility, while the genetic causal scenario he considers is too crude to deserve any discussion. "Is there a single gene that both causes its bearer to become violent and also sends him to live in a decaying inner city?" Well, no!

Pitting an initially promising environmentalist account against a glaringly ridiculous hereditarian alternative creates the appearance that the debate is effectively over and that only people with some sinister non-cognitive motivation could continue to support a genetic explanation. With one side in the controversy being distorted beyond recognition and pictured as a ludicrous non-starter, the other side wins by default.

It is precisely in this way, through a highly tendentious presentation and without making any connection with the relevant scholarly literature, that the received wisdom about the absolute defeat of hereditarianism has spread across philosophy as a field with such intensity that even people with no demonstrated expertise in biology, psychology or behavior genetics feel entitled and confident enough to inform the public about the "correct" scientific view.

For instance, on the website AskPhilophers.org, where a group of highly respected philosophers answers questions about various philosophy-related issues, someone recently asked: "If people of different races can have clear physical difference (appearance, or even immunities to certain diseases), could this not also mean there could be differences in ability to learn, or mental differences altogether?" 
A very brief answer that left no room for doubt came from Richard Heck, a leading philosopher of language and logic: "Of course there could be all kinds of differences between races, including differences in native intelligence, ability to learn, and so forth. The only significant question is whether there are such differences, and there has never been any decent reason to believe that there are" (the last emphasis mine).

Despite the authoritative tone of voice, Heck has never published anything even remotely related to the topic of racial differences in IQ. Nor is there any indication that he is sufficiently acquainted with pertinent research to be in the position to make such a sweeping condemnation of one whole side in this long raging scientific controversy. Besides, Heck's claim that there has never been any decent reason to accept hereditarianism in this debate is hard to square with the fact that the view he dismisses so hastily has been supported not only by the big names in the history of biology like Charles Darwin, H. J. Muller, R. A. Fisher, J. B. S. Haldane, A. H. Sturtevant, Julian Huxley, W. D. Hamilton, James Watson and Francis Crick, but also by many reputable and very sophisticated contemporary scholars like Arthur Jensen, Linda Gottfredson, John Loehlin, Richard Herrnstein, Charles Murray, David Rowe, Vincent Sarich, David Bartholomew, James Crow, etc. Now it is possible, of course, that all these scientists were just motivated by visceral racism and that they had "no decent reasons" for their views, but I will assume that this possibility should not be taken seriously.

\section{Conclusion}

My aim in this paper was not to prove the biological reality of race. Rather, more modestly, I have tried to show that typical attempts to disconnect the concept of race from genetics have too quickly and too uncritically been accepted by many "race critics", including most philosophers of science who have discussed this issue. The arguments for deconstructing race are fundamentally unsound because they ignore, misinterpret or distort relevant scientific facts. Therefore, it is time to abandon the mantra about the biological meaninglessness of race. Instead of wasting our time on "refuting" straw-man positions dredged from a distant past or from fiction, we should deal with the strongest contemporary attempts to rehabilitate race that are scientifically respectable and genetically informed. Philosophers (and others) have too long tried to destroy the scientific notion of race in different ways; the point, however, is to understand it.

Acknowledgments I would like to thank Rafael DeClercq, A. W. F. Edwards, Charles Murray, Alex Rosenberg, Omri Tal and Jiji Zhang for useful comments on earlier drafts.

\section{References}

Andreasen RO (1998) A new perspective on the race debate. Br J Philos Sci 49:199-225

Andreasen RO (2000) Race: biological reality or social contract? Philos Sci 67:S653-S666

Andreasen RO (2004) The cladistic race concept: a defense. Biol Philos 19:425-442 
Andreasen RO (2005) The meaning of 'race': folk conceptions and the new biology of race. J Philos 102:94-106

Andreasen RO (2008) The concept of race in medicine. In: Ruse M (ed) The Oxford handbook of philosophy of biology. Oxford University Press, Oxford

Appiah KA (1990) Racisms. In: Goldberg DT (ed) Anatomy of racism. University of Minnesota Press, Minneapolis

Appiah KA (1996) Race, culture, identity: misunderstood connections. In: Peterson GB (ed) The Tanner lectures on human values, vol 17. University of Utah Press, Salt Lake City, pp 51-136

Appiah KA (1999) Why there are no races. In: Harris L (ed) Racism. Humanity Press, Amherst

Appiah KA (2006) How to decide if races exist. Proc Aristot Soc 106:363-380

Appiah KA, Gutman A (1998) Color conscious. Princeton University Press, Princeton

Barbujani G (2005) Human races: classifying people vs understanding diversity. Curr Genomics 6:215-226

Block NJ (1995) How heritability misleads about race. Cognition 56:99-128

Blumenbach JF (2005) On the natural variety of mankind. Adamant Media Corporation, Boston

Bodmer WF, Cavalli-Sforza LL (1976) Genetics, evolution and man. W. H. Freeman, San Francisco

Bonham VL et al (2005) Race and ethnicity in the genome era: the complexity of the constructs. Am Psychol 60:9-15

Brown RA, Armelagos G (2001) Apportionment of racial diversity: a review. Evol Anthropol 10:34-40

Brues AM (1990) The once and future diagnosis of race. In: Gill GW, Rhine S (eds) Skeletal attributions of race. Maxwell Museum of Anthropology, Albuquerque

Cavalli-Sforza LL et al (1994) The history and geography of human genes. Princeton University Press, Prinnceton

Collins FS (2004) What we do and don't know about 'race', 'ethnicity', genetics and health at the dawn of the genome era. Nat Genet 36:S13-S15

Diamond J (1994) Race without color. Discover (November): 82-89

Diamond J (2005) Guns, germs and steel. PBS. Accessed 12 May 2009, http://video.google.com/ videoplay?docid=-4008293090480628280

Dummett M (2004) The nature of racism. In: Levine MP, Pataki T (eds) Racism in mind. Cornell University Press, Ithaca

Edwards AWF (2003) Human genetic diversity: Lewontin's fallacy. BioEssays 25:798-801

Edwards AWF (undated) Race, reason and rubbish. Unpublished manuscript

Gill GW (1990) Introduction. In: Gill GW, Rhine S (eds) Skeletal attribution of race. Maxwell Museum of Anthropology, Albuquerque

Gill GW (2000) Does race exist? A proponent's perspective. PBS. Accessed 8 May 2009, http://www. pbs.org/wgbh/nova/first/gill.html

Gissis SB (2008) When is 'race' a race? 1946-2003. Stud Hist Philos Biol Biomed Sci 39:437-450

Gitschier J (2005) The whole side of it—an interview with Neil Risch. PLoS Genet 1:3-5

Glasgow J (2009) A theory of race. Routledge, New York

Hacking I (2005) Why race still matters. Daedalus (Winter): 102-116

Hacking I (2006) Genetics, biosocial groups and the future of identity. Daedalus (Fall): 81-95

Hardimon M (2003) The ordinary concept of race. Journal of Philosophy 100:437-455

Harpending HC (2000) Review of taboo: why black athletes dominate sports and why we're afraid to talk about it. Popul Environ 22:83-89

Haslanger S (2005) You mixed? Racial identity without racial biology. In: Haslanger S, Witt C (eds) Adoption matters: philosophical and feminist essays. Cornell University Press, Ithaca

Hull D (1998) Species, subspecies, and races. Soc Res 65:351-367

James M (2008) Race. Stanford Encyclopedia of Philosophy. Accessed 1 May 2009, http://plato. stanford.edu/entries/race/

Kitcher P (2003) In Mendel's mirror: philosophical refelections on biology. Oxford University Press, Oxford

Kitcher P (2007) Does 'race' have a future? Philos Public Aff 35(4):293-317

Klein J, Takahata N (2002) Where do we come from? The molecular evidence for human descent. Springer, Berlin

Konigsberg LW et al (2009) Estimation and evidence in forensic anthropology: sex and race. Am J Phys Anthropol 139:77-90

Levin M (1997) Why race matters. Praeger, New York

Lewontin RC (1972) The apportionment of human diversity. Evol Biol 6:381-398 
Lewontin R (1987) Are the races different? In: Gill D, Levidow L (eds) Anti-racist science teaching. Free Association Books, London

Livingstone FB (1962) On the non-existence of human races. Curr Anthropol 3:279

Machery E, Faucher L (2005) Social construction and the concept of race. Philos Sci 72:1208-1219

Mallon R (2006) 'Race': normative, not metaphysical or semantic. Ethics 116:525-551

Mead M (ed) (1968) Science and the concept of race. Columbia University Press, New York

Mitton JB (1977) Genetic differentiation of races of man as judged by single-locus and multilocus analyses. Am Nat 111:203-212

Mitton JB (1978) Measurement of differentiation: reply to Lewontin, Powell, and Taylor. Am Nat 112:1142-1144

Ousley S et al (2009) Understanding race and human variation: why forensic anthropologists are good at identifying race. Am J Phys Anthropol 139:68-76

Pigliucci M, Kaplan J (2003) On the concept of biological race and its apllicability to humans. Philos Sci $70: 1161-1171$

Richardson RC (2000) Review of M. Levin's why race matters. Ethics 110:847-848

Ridley M (2004) Evolution. Blackwell, Oxford

Risch N et al (2002) Categorization of humans in biomedical research: genes, race and disease. Genome Biol 3:1-12

Rosenberg NA et al (2002) Genetic structure of human populations. Science 298:2381-2385

Rushton JP, Jensen AR (2005) Thirty years of research on race differences in cognitive ability. Psychol Public Policy Law 11:235-294

Sauer NJ (1992) Forensic anthropology and the concept of race: if races do not exist, why are forensic anthropologists so good at identifying them? Soc Sci Med 34:107-111

Schwartz RS (2001) Racial profiling in medical research. N Engl J Med 344:1392-1393

Tang $\mathrm{H}$ et al (2005) Genetic structure, self-identified race/ethnicity, and confounding in case-control association studies. Am J Hum Genet 76:268-275

Witherspoon DJ et al (2007) Genetic similarities within and between human populations. Genetics 176:351-359

Zack N (2002) Philosophy of science and race. Routledge, New York 